\title{
Small intestinal permeability and orocaecal transit time in cystic fibrosis
}

\author{
A M Dalzell, N S Freestone, D Billington, D P Heaf
}

\begin{abstract}
Cellobiose and mannitol were used as probe molecules to measure intestinal permeability in $\mathbf{3 6}$ children with cystic fibrosis, and 25 age matched controls. Orocaecal transit was also evaluated for each subject using the lactulose/ hydrogen breath test. There was a fourfold increase in permeability to disaccharide (cellobiose) in patients with cystic fibrosis, but permeability to the monosaccharide (mannitol) was similar to controls. The orocaecal transit time of lactulose was prolonged in patients with cystic fibrosis, but was unrelated to the percentage excretion of cellobiose or mannitol in cystic fibrosis patients or control subjects.
\end{abstract}

The permeability of the small intestine has been studied in a wide variety of intestinal and extraintestinal diseases, most notably in coeliac disease. ${ }^{1}$ The non-invasive, dual sugar permeability test uses a combination of a disaccharide (usually cellobiose or lactulose) and a monosaccharide (usually mannitol or rhamnose)..$^{2-4}$ These molecules have little or no affinity for mechanisms of mediated intestinal uptake and are essentially metabolically inert. The monosaccharide (molecular weight 180, molecular volume $-0.2 \mathrm{~nm}^{3}$ ) is absorbed by transcellular diffusion through channels of finite dimensions in the enterocyte plasma membrane while the disaccharide (molecular weight 342 , molecular volume $>0.3 \mathrm{~nm}^{3}$ ) is excluded from these channels and is absorbed to a smaller extent by a paracellular route across tight junctions between adjacent enterocytes. ${ }^{5}$ Thus in coeliac disease, where villous atrophy exists, the absorption of the monosaccharide is decreased due to reduced absorptive surface area while the absorption of the disaccharide is increased. This makes the test a sensitive indicator of malabsorption in coeliac disease. Abnormalities of intestinal permeability have also been demonstrated using the dual sugar absorption test in other gastrointestinal diseases such as infective gastroenteritis ${ }^{6}$ and Crohn's disease, ${ }^{7}$ and even in burns patients with sepsis. ${ }^{8}$

In cystic fibrosis there are many factors that may influence the uptake of intraluminal contents, such as pancreatic insufficiency, abnormal mucosal mucus, ${ }^{9}$ altered transcellular transport mechanisms, ${ }^{10}$ and altered transit time. ${ }^{11}$ The increased uptake and urinary excretion of intact disaccharides after an oral load of lactose and sucrose by patients with cystic fibrosis was first recorded by Gibbons in 1969,12 and the orocaecal transit time in adults with cystic fibrosis has been shown to be prolonged using the lactulosehydrogen breath test. ${ }^{11}$

The purpose of this study was to evaluate the association between small intestinal permeability (using cellobiose and mannitol as probes) and the orocaecal transit time (as measured by the lactulose/hydrogen breath test) in children with cystic fibrosis and in an age matched control population.

\section{Subjects and methods}

Thirty six children with cystic fibrosis were studied. There were 17 boys and 19 girls, and their mean age was 11.3 years (range 5.5-16.0 years). Two positive Gibson-Cooke sweat tests confirmed the diagnosis of cystic fibrosis, supported by pulmonary and gastrointestinal symptoms in each case. Steatorrhoea was observed in all individuals and pancreatic enzyme supplements were taken by each patient. In addition, all patients took flucloxacillin, as prophylaxis against staphylococcal colonisation, and multivitamins and vitamin $\mathrm{E}$ in view of their malabsorptive features. No additional antibiotics were taken for the week preceding either test.

Twenty five asymptomatic siblings of children with cystic fibrosis served as control subjects. There were 13 boys and 12 girls and their mean age was $10 \cdot 7$ years (range $5 \cdot 3-16 \cdot 3$ years).

\section{TEST PROCEDURES}

Each patient and matched control performed a cellobiose/mannitol differential sugar absorption test and a lactulose/hydrogen breath test on separate occasions at least two weeks apart. The differential sugar tests were supervised by an adult either at home or as an inpatient. All lactulose/hydrogen breath tests were conducted by the same investigator (AMD).

\section{CELLOBIOSE/MANNITOL TEST}

After an overnight fast, $2 \mathrm{~g}$ of mannitol, $5 \mathrm{~g}$ of cellobiose, and $20 \mathrm{~g}$ of both sucrose and lactose as osmotic fillers was dissolved in $100 \mathrm{ml}$ of water and ingested. All urine voided over the subsequent five hours was collected, and its volume was recorded. Thiomersal (final concentration $25 \mu \mathrm{mol} / \mathrm{l}$ ) was added as preservative to a portion which was stored at $-20^{\circ} \mathrm{C}$ until analysis. Subjects fasted for the duration of the urine collection, except that up to $500 \mathrm{ml}$ of water was allowed after ingestion of the sugars.

ANALYTICAL METHODS

Mannitol in urine was estimated as its 
trimethylsilyl-derivative by gas-liquid chromatography using $\alpha$-methylglucose as internal standard. ${ }^{13}$ A Pye-Unicam PU 4500 gas chromatograph fitted with flame ionisation detectors and linked to a Pye-Unicam PU4810 computing integrator was used. The column $(2 \mathrm{~m}, 3 \mathrm{~mm}$ inner diameter) used was $10 \%$ OV-17 on gas chrom $Q$ and column conditions were as follows: oven temperature $190^{\circ} \mathrm{C}$, injector temperature $210^{\circ} \mathrm{C}$, detector temperature $350^{\circ} \mathrm{C}$, carrier gas (nitrogen) flow rate $40 \mathrm{ml} /$ minute. Cellobiose in urine was determined by enzymic hydrolysis to glucose by $\beta$-glucosidase followed by detection of glucose by the hexokinase method using a test kit (Boehringer). ${ }^{14}$

\section{LACTULOSE/HYDROGEN BREATH TEST}

After an overnight fast, a basal end expired hydrogen value was obtained through a $\mathrm{T}$ piece attached to a mask. A $20 \mathrm{ml}$ aliquot was obtained, and subsequently paired samples at 10 minute intervals were analysed using an exhaled hydrogen monitor (Gas Measurements Ltd). The test was conducted for up to 250 minutes after the ingestion of $10 \mathrm{~g}$ lactulose, and a $50 \%$ rise above the basal value was regarded as evidence of the transit of the head of the lactulose bolus into the caecum.

\section{STATISTICAL ANALYSIS}

Results are presented as mean (SEM) percentage recoveries of each probe molecule in a five hour urine collection, or the mean (SEM) orocaecal transit time of lactulose. Normal ranges represent the mean value and 2 SD. Differences between control and cystic fibrosis patients were assessed using Student's $t$ test and Wilcoxon signed rank test.

\section{Results}

Although lactulose and the mixed sugar solution
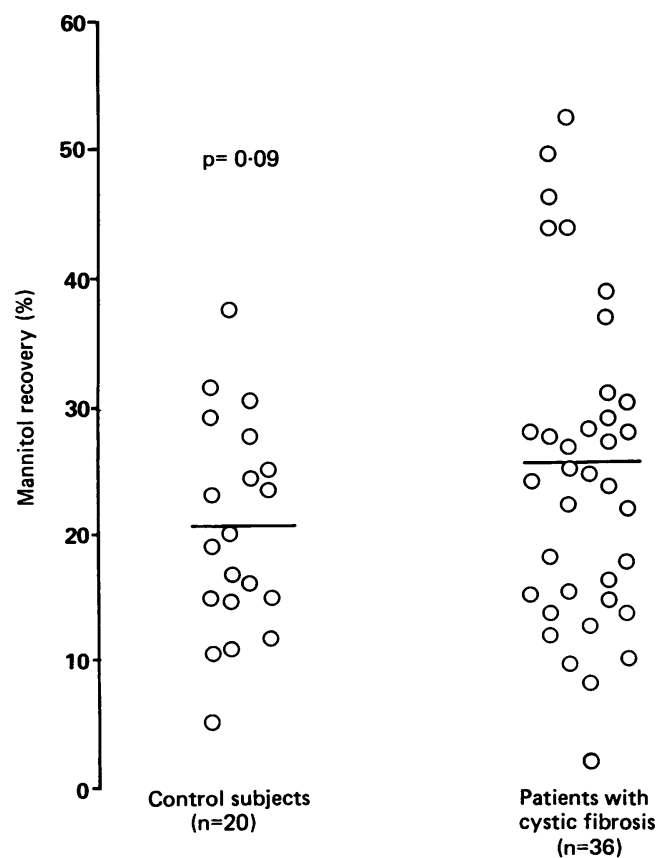

Figure 1 Percentage mannitol recoveries in patients with cystic fibrosis and control subjects. were said to be unpalatable by some subjects, both tests were tolerated without ill effect.

\section{CELLOBIOSE/MANNITOL TEST}

Thirty six patients with cystic fibrosis and 20 control subjects completed the differential sugar absorption test.

The percentage recovery of mannitol in urine collected for five hours from control subjects was $20.5(1.9) \%$ giving a normal range of $3 \cdot 9-37 \cdot 2 \%$ (fig 1 ). The percentage recovery of mannitol in patients with cystic fibrosis was mean $24 \cdot 7(2 \cdot 1) \%$ and was not significantly different from controls. One out of 36 cystic fibrosis patients had a mannitol recovery below the normal range while five out of $36(14 \%)$ had mannitol recoveries above the normal range.

The percentage recovery of cellobiose from control subjects was $0.35(0.05) \%$ giving an upper limit of normal of 0.80 (fig 2). Cellobiose recovery in cystic patients was significantly greater than controls $(p<0.01)$ and was 1.14 $(0 \cdot 17) \%$. Twenty two out of 36 cystic fibrosis patients had a cellobiose recovery above the upper limit of normal.

When the percentage recovery of cellobiose is expressed as a ratio to that of mannitol, the mean value for control subjects was 0.020 $(0.004)$ giving an upper limit of normal of 0.056 (fig 3). The mean (SEM) cellobiose:mannitol ratio in cystic fibrosis patients was 0.059 (0.010) and 13 out of 36 had ratios above the upper limit of normal.

\section{LACTULOSE/HYDROGEN BREATH TEST}

Basal breath hydrogen values were significantly greater $(p<0.01)$ in cystic fibrosis patients (mean 32(3)ppm) compared with controls (mean 22(2)ppm). The upper limit of normal for baseline hydrogen values within the control group was $44 \mathrm{ppm}$.

Twenty eight patients with cystic fibrosis completed the breath hydrogen test, 11 achieving a definable endpoint within 180 minutes, while 17 failed to achieve an endpoint and were given an orocaecal transit time according to the time at which the test was terminated. Only

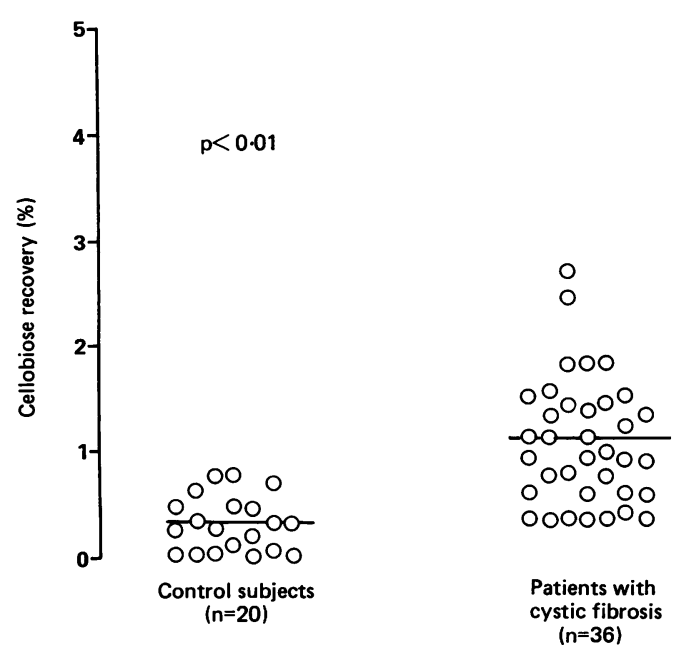

Figure 2 Percentage cellobiose recoveries in patients with cystic fibrosis and control subjects. 


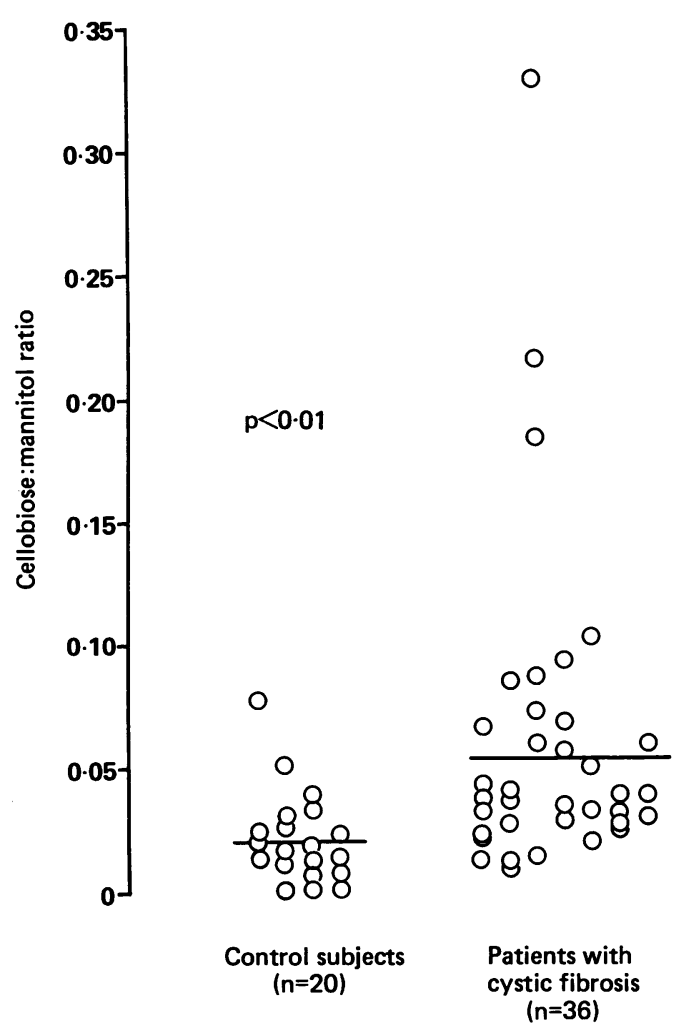

Figure 3 Cellobiose:mannitol ratios in five hour urine collections in patients with cystic fibrosis and control subjects.

patients and controls who had baseline hydrogen concentrations below $30 \mathrm{ppm}$, and whose values throughout the test did not drop below basal values, were included in the analysis of orocaecal transit time.

Twenty two controls completed the breath hydrogen test within 180 minutes, and only three subjects yielded no definable endpoint within that time. The mean (SEM) values for

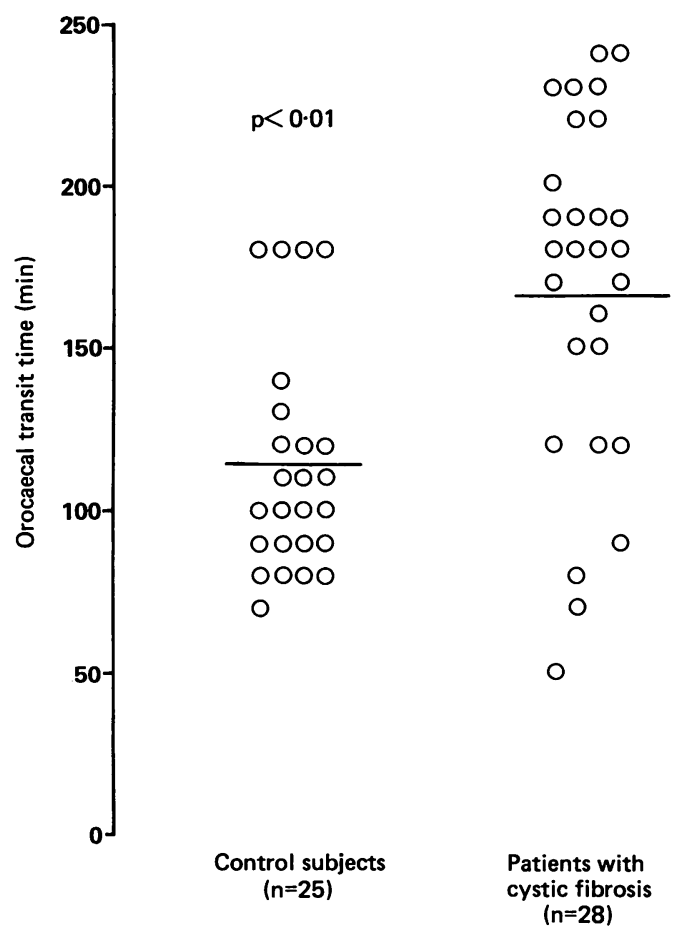

Figure 4 Orocaecal transit times of lactulose in patients with cystic fibrosis and control subjects. the orocaecal transit of lactulose were $168(9 \cdot 8)$ minutes for patients with cystic fibrosis, and 113 (7) minutes for controls ( $p<0.01$ ) (fig 4).

If the results of subjects in each group who failed to achieve a test endpoint are discarded, there is still a significant difference between the two groups $(\mathrm{p}<0.05)$.

There was no correlation between the orocaecal transit time of lactulose and the percentage recovery of mannitol $(r=0.093)$ and cellobiose $(r=0 \cdot 16)$ in control subjects or with the percentage recovery of mannitol $(r=-0.36)$ and cellobiose $(r=-0.33)$ in patients with cystic fibrosis.

\section{Discussion}

When the intestinal mucosa is damaged, normal transport mechanisms are disrupted and large molecules enter the blood more readily while if villous atrophy exists, as in coeliac disease, absorption of small molecules is decreased. Thus in the differential absorption test, expressing the percentage recovery of the disaccharide as a ratio of that of the monosaccharide provides a sensitive indicator of malabsorption. ${ }^{34}$ The advantage of the differential absorption test over permeability tests using a single probe molecule is that the influence of certain nonintestinal factors such as renal impairment or gastric and bladder emptying are eliminated. For example, in the elderly, the recovery of both rhamnose and cellobiose are decreased, due to reduced glomerular filtration rate, while the cellobiose:rhamnose ratio is normal. ${ }^{15}$ In addition, treatment response may be judged by a return to normal values once patients with coeliac disease are treated with a gluten free diet $^{16}$ and correlates well with disease activity in Crohn's disease. ${ }^{7}$

Leclercq-Foucart et al carried out a rhamnose/lactulose sugar absorption test in a relatively small sample of 10 children with cystic fibrosis and showed a tenfold increase in the percentage recovery of the disaccharide. ${ }^{17}$ This is in agreement with, but considerably greater than, the fourfold increase in the recovery of cellobiose reported in this study. In addition, intestinal permeability to ${ }^{51} \mathrm{Cr}$ EDTA, a single probe molecule that is also taken up by the paracellular route, is increased in cystic fibrosis (unpublished observations cited in Leclercq-Foucart et $a^{17}{ }^{17}$ ). Leclercq-Foucart et al also reported an approximate doubling of rhamnose recovery in cystic fibrosis, however, although this effect was not always present. ${ }^{17}$ This is in contrast with our results where mannitol recovery was similar in control subjects and cystic fibrosis patients, although we did find five out of 36 (14\%) patients whose mannitol recovery was above the upper limit of normal. It is noteworthy that these authors reported a very low five hour urinary recovery of rhamnose in controls $(7 \cdot 6 \%),{ }^{17}$ while most studies using mannitol in both adults and children report control recoveries of approximately $20 \%$. ${ }^{14}{ }^{18-20}$ Taken overall, these results suggest that the paracellular pathway leaks large molecules more freely, while the passive transcellular uptake of small molecules is essentially pre- 
served in cystic fibrosis. This is supported by histological findings of normal brush border morphology in patients with cystic fibrosis. ${ }^{21}$

The orocaecal transit time of lactulose has been shown to be prolonged in adults with cystic fibrosis, ${ }^{11}$ and we have shown this in children with cystic fibrosis using the same technique. It would be expected that prolonged transit through the small bowel should affect both sugars equally such that the percentage recoveries of mannitol and cellobiose would be increased to the same extent while the cellobiose:mannitol ratio would be unaffected. Indeed, Cobden et al have shown that the rates of gastric emptying and small intestine transit do not affect the cellobiose:mannitol recovery ratio. ${ }^{22}$ In this study we have shown that the cellobiose:mannitol ratio was increased threefold with 13 out of 36 patients with cystic fibrosis having ratios above the upper limit of normal. In addition, there was no significant correlation between the percentage recovery of monosaccharide or disaccharide and orocaecal transit time in both normal controls or patients with cystic fibrosis. Thus the observed increase in cellobiose recovery is not due to the prolonged orocaecal transit time observed in cystic fibrosis patients.

The gastrointestinal manifestations of cystic fibrosis are muliple and complex. ${ }^{23}$ Many factors may influence the absorption of sugars such as hyperacidity and the presence of pancreatic enzymes. In common with other pathological conditions involving the small bowel, patients with cystic fibrosis show an increased permeability to disaccharides that is unrelated to transit time. We do not believe that intestinal mucus could be causing the observed difference as one might expect a parallel response by both sugars, and as the sugar test has a normal profile in patients with pancreatic insufficiency not caused by cystic fibrosis, ${ }^{19}$ it seems unlikely that pancreatic enzymes or $\mathrm{pH}$ contribute to the phenomenon. We postulate that the observed difference in sugar absorption noted in patients with cystic fibrosis is related specifically to disordered paracellular transport mechanisms that lead to the increased disaccharide uptake. Indeed, tight junction abnormalities of epithelial cells of the pancreas, respiratory tract, intestine, and gall bladder have been demonstrated in fetuses with cystic fibrosis. ${ }^{24}$
AMD is in receipt of a cystic fibrosis research fellowship. NSF is supported by a grant from the Mersey Regional Health Authority.

1 Editorial. Intestinal permeability. Lancet 1985;i:256-8.

2 Menzies IS, Laker M, Pounder R, et al. Abnormal intestinal permeability to sugars in villous atrophy. Lancet 1979;ii: $1107-9$.

3 Juby LD, Rothwell J, Axon ATR. Lactulose/mannitol test: an ideal screen for celiac disease. Gastroenterology 1989;96: $79-85$.

4 Juby LD, Rothwell J, Axon ATR. Cellobiose/mannitol sugar test-a sensitive tubeless test for coeliac disease: results on 1010 unselected patients. Gut 1989;30:476-80.

5 Hamilton I, Rothwell J, Archer D, Axon ATR. Permeability of the rat small intestine to carbohydrate probe molecules. Clin Sci 1987;73:189-96.

6 Ford RPK, Menzies IS, Philips AD, Walker-Smith JA, Turner MW. Intestinal sugar permeability: relationship to diarrhoeal disease and small bowel morphology. $\mathcal{F}$ Pediatr Gastroenterol Nutr 1985;4:568-74.

7 Murphy MS, Eastham EJ, Nelson R, Pearson ADJ, Laker MF. Intestinal permeability in Crohn's disease. Arch Dis Child 1989;64:321-5.

8 Ziegler TR, Smith RJ, O'Dwyer ST, Demling RH, Wilmore DW. Increased intestinal permeability associated with DW. Increased intestinal permeability associated with

9 Dische Z, di Sant'Agnese P, Pallavicini C, Youlos J. Com position of mucoprotein fractions from duodenal fluid of patients with cystic fibrosis of the pancreas and from controls. Pediatrics 1959;24:74-91.

10 Hopfer U. Pathophysiological considerations relevant to intestinal obstruction in cystic fibrosis. In: Quinton PM, Martinez JR, Hopfer U, eds. Fluid and electrolyte abnormalities in exacrine glands in cystic fibrosis. San Francisco: San Francisco Press, 1982:241-51.

11 Bali A, Stableforth D, Asquith P. Prolonged small-intestinal transit time in cystic fibrosis. Br Med $\mathscr{f}$ 1983;287:1011-3.

12 Gibbons ISE. Disaccharides and cystic fibrosis of the pancreas. Arch Dis Child 1969;44:63-8.

13 Laker MK, Mount JN. Mannitol estimation in biologica fluids by gas liquid chromatography of trimethylsilyl fluids by gas liquid chromatography

14 Strobel S, Brydon WG, Ferguson A. Cellobiose/mannitol sugar permeability test complements biopsy histopathology in clinical investigation of the jejunum. Gut 1984;25: 1241-6.

15 Saweirs WM, Andrews DJ, Low-Beer TS. The double sugar test of intestinal permeability in the elderly. Age Ageing 1985;14:312-5.

16 Hamilton I, Cobden I, Rothwell J, Axon ATR. Intestina permeability in coeliac disease: the response to gluten with drawal and single-dose gluten challenge. Gut 1982;23: 202-10.

17 Leclercq-Foucart J, Forget PP, Van Cutsem JL. Lactuloserhamnose intestinal permeability in children with cystic fibrosis. I Pediatr Gastroenterol Nutr 1987;6:66-70.

18 Martines D, Morris AI, Gilmore IT, et al. Comparison between the cellobiose/mannitol and ${ }^{51} \mathrm{Cr}$-labelled ethylenediaminetetra-acetate absorption tests in the detecethylenediaminetetra-acetate absorption tests in

19 Cobden I, Rothwell J, Axon ATR. Intestinal permeability and screening tests for coeliac disease. Gut 1980;21:512-8.

20 Hodges S, Ashmore SP, Patel HR, Tanner MS. Cellobiose: mannitol differential permeability in small bowel disease. mannitol differential permeability

21 Freye HB, Kurtz SM, Spock A, Capp MP. Light and electron microscopic examination of the small bowel of children with cystic fibrosis. Pediatrics 1964;64:575-9.

22 Cobden I, Hamilton I, Rothwell J, Axon ATR. Cellobiose mannitol test: physiological properties of probe molecules and influence of extraneous factors. Clin Chim Acta 1985; 148:53-62.

23 Park RW, Grand RJ. Gastrointestinal manifestations of cystic fibrosis: a review. Gastroenterology 1981;81:1143-61.

24 Gosden CM, Gosden JR. Fetal abnormalities in cystic fibrosis suggest a deficiency in proteolysis of cholecystokinin. Lancet 1984;ii:541-6. 